\title{
Progressos recentes e novas perspectivas em farmacoterapia da obesidade
}

\author{
Recent progress and novel perspectives on obesity pharmacotherapy
}

André M. Faria', Marcio C. Mancini ${ }^{1,2}$, Maria Edna de Melo ${ }^{1,2}$, Cintia Cercato', Alfredo Halpern'

${ }^{1}$ Grupo de Obesidade e Síndrome Metabólica, Disciplina de Endocrinologia e Metabologia, Hospital das Clínicas, Faculdade de Medicina da Universidade de São Paulo (HC-FMUSP), São Paulo, SP, Brasil

${ }^{2}$ Laboratório de Carboidratos e Radioimunoensaio/LIM 18 da Faculdade de Medicina da Universidade de São Paulo (FMUSP).
Correspondência para: Marcio C. Mancini

Secretaria da Disciplina de Endocrinologia e Metabologia Av. Dr. Enéas de Carvalho Aguiar, 255 05403-000 - São Paulo, SP, Brasil mmancini@usp.br

Recebido em 17/Mar/2010 Aceito em 24/Abr/2010

\section{SUMÁRIO}

O aumento da prevalência da obesidade, nas últimas décadas, é alarmante, o que implica um grande número de pacientes sob risco de complicações metabólicas e cardiovasculares associadas. A eficácia modesta a longo prazo das modificações de estilo de vida isoladamente exige a necessidade de intervenções mais agressivas, seja por meio do uso adjuvante de medicamentos ou da abordagem mais radical cirúrgica. A cirurgia bariátrica, embora até hoje tenha se mostrado o método mais efetivo de tratamento dessa enfermidade, pode estar associada a complicações nutricionais e metabólicas ainda não totalmente esclarecidas. Contrasta com esse fato a disponibilidade limitada de agentes antiobesidade atualmente no mercado, além de fatos históricos que envolveram a suspensão de alguns fármacos previamente existentes, por questões de segurança. Este artigo tem como objetivo apresentar dados recentes de estudos clínicos de novas drogas propostas para o tratamento da obesidade com perspectivas breves de serem lançadas no mercado, caso passem pela aprovação das agências regulatórias. Nesta revisão serão discutidas a eficácia e a segurança desses fármacos, que incluem a lorcaserina (agonista serotoninérgico seletivo 5-HT2c), tesofensina (inibidor triplo de recaptação de monoaminas), liraglutide (análogo do GLP-1) e cetilistate (inibidor de lipases gastrointestinais), além das combinações de bupropiona/naltrexona, bupropiona/zonisamida, fentermina/topiramato e pramlintide/metreleptina. Arq Bras Endocrinol Metab. 2010;54(6):516-29

\section{Descritores}

Obesidade; farmacoterapia; agentes antiobesidade

\section{SUMMARY}

Obesity prevalence has risen dramatically over the past decades, which poses a great number of patients at risk of metabolic and cardiovascular complications. Long-term efficacy of lifestyle modification isolated has shown to be modest which, therefore, urges the need of more aggressive interventions such as adjuvant pharmacotherapy or the more radical surgical approach. Bariatric surgery has proven to date to be the most effective treatment, although it may be associated with nutritional and metabolic complications not yet completely recognized. By contrast, there is limited availability of antiobesity agents currently in the market, as well as historical facts involving the suspension of previously existing medications due to safety concerns. This article aims to present recent data on clinical trials of novel weight-loss drugs with short perspective to enter the market, if approved by the regulatory agencies. This review will discuss the efficacy and safety of these compounds, which include lorcaserin (selective serotonin 5-HT2c agonist), tesofensine (triple monoamine reuptake inhibitor), liraglutide (GLP-1 analogue) and cetilistat (gastrointestinal lipase inhibitor), as well as the combination therapies of bupropion/ naltrexone, bupropion/zonisamide, phentermine/topiramate and pramlintide/metreleptin. Ara Bras Endocrinol Metab. 2010;54(6):516-29

\section{Keywords}

Obesity; drug therapy; anti-obesity agents 


\section{INTRODUÇÃO}

A prevalência da obesidade, definida como índice de massa corporal (IMC) $\geq 30 \mathrm{~kg} / \mathrm{m}^{2}$, aumentou dramaticamente nas últimas quatro décadas, atingindo cerca de um terço das populações de países desenvolvidos da América do Norte e Europa, com índices de sobrepeso (IMC $\geq 25 \mathrm{~kg} / \mathrm{m}^{2}$ ) de mais de $40 \%$ da população em nosso meio. Isso se associa a um aumento significativo de comorbidades, tais como diabetes melito tipo 2 (DM2), hipertensão arterial sistêmica (HAS), doença cardiovascular, apneia do sono, doenças musculoesqueléticas e neoplasias. Estudos mostram que, mesmo uma perda de peso pequena de $5 \%-10 \%$ do peso corporal, independentemente de como for atingida, é associada com melhora do perfil de risco cardiovascular e uma menor incidência de DM2.

Nos últimos anos, a obesidade tem sido considerada uma doença metabólica e neuroendócrina que resulta da interface entre um ambiente obesogênico e uma predisposição genética intrínseca. A despeito disso, modificações do estilo de vida propostas no tratamento da obesidade são fundamentais e podem ser efetivas, mas isoladamente as taxas de sucesso a longo prazo costumam ser baixas. $\mathrm{O}$ uso de medicamentos para perda de peso é efetivo a longo prazo, mas, após um ano de tratamento, as drogas mais utilizadas atualmente (sibutramina e orlistate) geram uma perda de peso subtraída do placebo em média de 3-5 $\mathrm{kg}(1,2)$. Essa pequena eficácia contrasta com a perda de peso atingida nos pacientes submetidos à cirurgia bariátrica (por exemplo, 20\%-25\% com bypass gástrico), resultando em uma redução significativa de comorbidades e aumento de longevidade (3). Portanto, faz-se necessário o desenvolvimento de novas drogas que possuam maior eficácia, associada a um perfil de segurança favorável e a um mínimo de efeitos colaterais. Recentemente, o campo do tratamento farmacológico da obesidade tem passado por um período de ebulição e uma série de novas drogas e combinações de drogas com diferentes propostas e mecanismos de ação encontra-se em estágio avançado de desenvolvimento.

Esta revisão tem por objetivo apresentar dados recentes da literatura sobre essas novas drogas e combinações. Para isso, este artigo será dividido em duas partes:

1) Monoterapia: novas drogas estudadas para uso isoladamente, compreendendo a lorcaserina, tesofensina, liraglutide e cetilistate.

2) Terapia combinada: uso de uma combinação de duas drogas com mecanismos de ação distintos com o intuito de promoverem efeito sinérgico na redução do peso corporal. Neste grupo, incluem-se as associações bupropiona/naltrexona, bupropiona/zonisamida, fentermina/topiramato e pramlintide/metreleptina.

Para uniformização dos achados apresentados e comparação entre as drogas estudadas, a perda de peso será descrita em redução percentual do peso inicial. Os dados serão expressos por meio da análise de intenção por tratar e haverá referência à perda de peso subtraída do placebo (PPSP), isto é, o quanto a medicação proposta é mais eficiente em reduzir o peso a mais do que somente as modificações de estilo de vida e a motivação do paciente.

\section{MONOTERAPIA}

\section{Lorcaserina}

É sabidamente conhecido o papel da via serotoninérgica como mecanismo de perda de peso. Vários agonistas dos receptores 5-HT mostraram-se efetivos na redução do peso corporal, como a fenfluramina e a dexfenfluramina. Essas duas medicações, que possuem atividade estimulatória não seletiva sobre os receptores 5 -HT acoplados à proteína G (5-HT2a, 5-HT2b e 5-HT2c), foram largamente utilizadas no passado como adjuvantes no tratamento da obesidade, notadamente em associação ao catecolaminérgico fentermina (combinação popularmente conhecida como “fen-phen") (4). Entretanto, ambas foram retiradas do mercado em 1997 após a descrição de uma série de 24 mulheres com valvulopatia cardíaca presumidamente associada ao uso da combinação "fen-phen" (5). Estudos retrospectivos subsequentes corroboraram esse achado, sendo a regurgitação aórtica a alteração valvular mais específica associada à estimulação não seletiva dos receptores 5-HT.

Com o reconhecimento de que a eficácia dos agonistas dos receptores 5-HT estava amplamente relacionada com o estímulo do receptor 5-HT2c e que a toxicidade valvular cardíaca era provavelmente associada ao estímulo do receptor 5-HT2b, esforços foram direcionados para o desenvolvimento de uma droga antiobesidade com seletividade para o receptor 5-HT2c.

A lorcaserina é uma molécula pequena com agonismo seletivo sobre o receptor serotoninérgico 5-HT2c (6). Essa substância possui seletividade funcional da ordem de 15 e 100 vezes mais pelo receptor 5-HT2c que pelos receptores 5-HT2a e 5-HT2b, respectivamente. $\mathrm{O}$ aumento da atividade serotoninérgica no sistema 
nervoso central (SNC) por meio do estímulo do receptor 5-HT2c modula o balanço calórico por intermédio da ativação da via do sistema POMC, promovendo o aumento do catabolismo pelos efetores de segunda ordem, tais como TRH, CRH, MC4R, entre outros. Estudos em animais sugerem que ratos com ausência do receptor 5-HT2c têm taxa metabólica basal diminuída, assim como hiperfagia e desregulação da saciedade. Em humanos, alguns estudos sugerem que o agonismo do receptor 5 -HT2c pode aumentar a taxa metabólica basal e a termogênese, enquanto outros não corroboram esse achado (7).

O estudo fase 3 denominado BLOOM randomizou 3.182 pacientes com IMC entre 30 e $45 \mathrm{~kg} / \mathrm{m}^{2}$ com ou sem comorbidades ou IMC entre 27 e $30 \mathrm{~kg} / \mathrm{m}^{2} \mathrm{com}$ pelo menos uma comorbidade, para uso de lorcaserina $10 \mathrm{mg}$ duas vezes ao dia ou placebo, por um período de 2 anos (8). Foram realizados ecocardiogramas no basal e em 6, 12, 18 e 24 meses após o início do estudo. Pacientes com valvulopatia no basal foram excluídos do estudo. Após um ano de tratamento, a PPSP foi de $3,6 \%$ (5,8\% no grupo ativo vs. $2,2 \%$ no grupo placebo). Quarenta e sete por cento dos pacientes tomando lorcaserina perderam pelo menos $5 \%$ do peso inicial, comparados a 20\% do grupo placebo. Após um ano de tratamento, houve melhora estatisticamente significativa de vários parâmetros de desfecho secundário, entre eles: pressão arterial (PA) sistólica e diastólica, frequência cardíaca (FC), colesterol total, LDL-colesterol, triglicérides, glicemia de jejum, insulina, proteína $\mathrm{C}$ reativa de alta sensibilidade e fibrinogênio. Posteriormente, foi feito um segundo estudo denominado BLOSSOM (8), com inclusão de mais 4.008 pacientes, que apresentou desfechos semelhantes tanto em termos de eficácia como de segurança e tolerabilidade da lorcaserina. Um terceiro estudo denominado BLOOM-DM está em andamento envolvendo pacientes obesos e com sobrepeso com DM2.

O tratamento com a lorcaserina foi bem tolerado, com poucos efeitos adversos e maior frequência em comparação ao grupo placebo. Os efeitos colaterais mais frequentes relatados no primeiro ano e as taxas nos pacientes lorcaserina e placebo, respectivamente, foram: cefaleia $(18,0 \%$ vs. $11,0 \%)$, infecção do trato respiratório superior $(14,8 \%$ vs. $11,9 \%)$, nasofaringite $(13,4 \%$ vs. $12,0 \%)$, sinusite $(7,2 \%$ vs. $8,2 \%)$ e náuseas $(7,5 \%$ vs. $5,4 \%)$. Efeitos adversos como depressão, ansiedade e ideação suicida foram infrequentes e com incidência semelhante em ambos os grupos. Mais pa- cientes tomando a lorcaserina completaram um ano de estudo, em relação ao placebo $(54,9 \%$ vs. $45,1 \%)$. A taxa de abandono por efeitos colaterais foi indiferente do placebo, tanto no primeiro como no segundo ano de tratamento $(7,1 \%$ vs. $6,7 \%$ e $3,0 \%$ vs. $3,0 \%$, respectivamente). Nesse estudo houve uma preocupação justificada com a questão do aparecimento de valvulopatia, porém após dois anos de uso da medicação às taxas de mudança de escore de regurgitação e desenvolvimento de nova valvulopatia foram semelhantes às do placebo (2,6\% vs. $2,7 \%$, respectivamente).

\section{Tesofensina}

A tesofensina é uma droga com propriedades de inibição da recaptação pré-sináptica de noradrenalina, dopamina e serotonina, originalmente desenvolvida para o tratamento de pacientes com doença de Parkinson e Alzheimer, que foi subsequentemente retirada dessa linha de desenvolvimento quando estudos mostraram eficácia limitada no tratamento desses distúrbios neurológicos. Entretanto, observou-se que um subgrupo de pacientes obesos expostos a essa medicação apresentou perda de peso não intencional de aproximadamente $4 \%$ em 14 semanas quando comparado ao grupo placebo, sem qualquer orientação dietética ou de estilo de vida (9). Ao promover inibição tripla de importantes neurotransmissores, a tesofensina promove inibição do apetite e aumento da saciedade. Postula-se também que o balanço energético negativo seja potencializado por um aumento do gasto energético secundário à termogênese aumentada, fato que está sendo testado em ensaios clínicos em andamento.

Tendo em vista esse efeito desejável em pacientes obesos com distúrbios neurológicos, foi desenhado um estudo fase 2 randomizado, duplo-cego, placebocontrolado, com duração de 24 semanas (TIPO-1), para avaliar a eficácia dessa medicação na redução do peso corporal de 203 pacientes com IMC entre $30 \mathrm{e}$ $40 \mathrm{~kg} / \mathrm{m}^{2}$ (10). Todos os participantes eram orientados a fazer uma dieta leve com déficit de $300 \mathrm{kcal} /$ dia, além de gradualmente aumentarem atividade física até 30 a 60 minutos diários. Os pacientes perderam uma média de $12,8 \mathrm{~kg}$ na dose de $1,0 \mathrm{mg}, 11,3 \mathrm{~kg}$ na de $0,5 \mathrm{mg} \mathrm{e}$ $6,7 \mathrm{~kg}$ na de $0,25 \mathrm{mg}$, comparados a $2,2 \mathrm{~kg}$ no grupo placebo. A PPSP foi de 4,5\%; 9,2\% e 10,6\% nos grupos de 0,$25 ; 0,5$ e $1,0 \mathrm{mg}$, respectivamente. No grupo que utilizou a dose de $0,5 \mathrm{mg}, 87 \%$ perderam mais de $5 \mathrm{~kg}$ e $53 \%$ perderam mais de $10 \mathrm{~kg}$ do peso inicial. Esses resultados correspondem a cerca do dobro da perda de 
peso produzida por outras medicações aprovadas para o tratamento da obesidade. A análise da composição corporal, por densitometria de corpo inteiro (DEXA), mostrou que a perda de peso era principalmente à custa de gordura, sem perda excessiva de massa magra. Consistente com a perda de peso, houve redução dos triglicérides e do colesterol total nas doses de 0,5 e 1,0 mg, assim como redução nos níveis de insulina e $\mathrm{HbAlc} e$ incremento da adiponectina.

A empresa farmacêutica que detém os direitos da tesofensina (NeuroSearch A/S) também reportou resultados preliminares de um estudo aberto de extensão do tratamento por 48 semanas (TIPO-4), em 140 pacientes que haviam completado o TIPO-1 (11). Foram incluídos pacientes tanto dos três grupos ativos da medicação como do grupo placebo e, após dois meses de wash-out da medicação, todos passaram a receber a dose de $0,5 \mathrm{mg}$. A análise interina de 24 semanas mostrou que os pacientes anteriormente tratados com a dose de $0,5 \mathrm{mg}$ apresentaram um perda total de peso de 13 a $14 \mathrm{~kg}$, incluindo o que eles haviam ganho no período de wash-out. Mais ainda, os pacientes que haviam sido alocados no grupo placebo no TIPO-l obtiveram uma perda de peso de $9,0 \mathrm{~kg}$ ao final das 24 semanas de tratamento (em adição aos 2,2 kg perdidos previamente), confirmando, portanto, a eficácia da dose de $0,5 \mathrm{mg}$ no manejo do peso sob condições similares de tratamento e duração.

Em geral, os efeitos colaterais da tesofensina são semelhantes aos observados com outras drogas antiobesidade. Vinte por cento dos pacientes com a dose de 1,0 mg abandonaram o estudo por conta de efeitos adversos de maior intensidade, em comparação com os $8 \%$ do grupo de $0,5 \mathrm{mg}$ e do grupo placebo. Sinais e sintomas como xerostomia, insônia, taquicardia, constipação, náuseas, diarreia, tonturas e elevação da PA e FC foram relatados e, geralmente, eram dose-dependentes. As doses de 0,25 e $0,5 \mathrm{mg}$ foram inócuas em relação a PA, enquanto a dose de $1,0 \mathrm{mg}$ aumentou significativamente a PA sistólica e diastólica em cerca de 7 e $6 \mathrm{mmHg}$, respectivamente. Houve um aumento dose-dependente da FC, variando de 5 a 8 batimentos por minuto. A dose de 1,0 $\mathrm{mg}$ foi associada com maior sentimento de raiva e hostilidade, e tanto a dose de 0,5 como de 1,0 mg correlacionou-se com maior grau de confusão mental. Contudo, houve uma melhora estatisticamente significativa na qualidade de vida global relacionada à perda de peso em todos os três grupos ativos de tratamento quando comparados ao grupo placebo. Isso foi relacionado com melhora da função física e autoestima. Alterações do humor foram mais frequentes nos pacientes tomando a medicação (humor elevado ou eufórico e humor deprimido), em particular com a dose de $1,0 \mathrm{mg}$. Não houve efeito negativo das doses de 0,25 e $0,5 \mathrm{mg}$ em relação à incidência de transtornos depressivos ou de ansiedade.

\section{Liraglutide}

O liraglutide é um análogo do GLP-1 com 97\% de homologia estrutural ao GLP-1 humano. O GLP-1 nativo tem uma meia-vida curta de 1 a 2 minutos, enquanto o liraglutide apresenta uma meia-vida de cerca de 13 horas e pode ser administrado uma vez ao dia por via subcutânea (12). Essa medicação foi inicialmente desenvolvida para o tratamento do DM2 e mostrou-se benéfica para o controle glicêmico em doses até $1,8 \mathrm{mg} /$ dia. Demonstrou, também, no tratamento de diabéticos tipo 2 , gerar uma perda de peso dose-dependente, e, ao mesmo tempo, diminuir as concentrações de HbAlc e melhorar a função da célula $\beta$ (13). Os mecanismos mediadores na redução de peso pelo liraglutide são provavelmente relacionados a uma combinação de efeitos no trato gastrointestinal (TGI) e no cérebro. O GLP-1 ativo inibe o apetite e o aporte energético tanto em indivíduos normais quanto em obesos, assim como em pacientes com DM2, além de retardar o esvaziamento gástrico (14). Comprovou-se a eficácia dessa droga também em modelos animais, com redução de peso e da ingestão alimentar em ratos e porquinhos tratados.

Considerando o potencial da medicação como adjuvante no tratamento da obesidade, mesmo em pacientes não diabéticos, desenvolveu-se um estudo para avaliar a eficácia, segurança e tolerabilidade do liraglutide no tratamento de pacientes obesos não diabéticos, com doses mais elevadas do que as previamente utilizadas para o tratamento do DM2 (15). Quinhentos e sessenta e quatro pacientes foram randomizados a receber liraglutide (1,2 mg, 1,8 mg, 2,4 $\mathrm{mg}$ ou $3,0 \mathrm{mg}$ uma vez ao dia por via subcutânea, $\mathrm{n}=90-95$ cada), placebo (uma vez ao dia por via subcutânea, $\mathrm{n}=98$ ) ou orlistate $(120 \mathrm{mg}$ três vezes ao dia por via oral, $\mathrm{n}=$ 95). Após a triagem, os pacientes recebiam placebo de modo único-cego por duas semanas e eram orientados a fazer uma dieta pobre em gordura com déficit de 500 $\mathrm{kcal} /$ dia e intensificação de atividade física. Nas quatro semanas subsequentes, realizava-se a titulação da dose do liraglutide e, posteriormente, cada grupo se mantinha com uma dose constante por 16 semanas. O tratamento com placebo era subdividido em quatro grupos 
com injeções de volumes diferentes, correspondente às quatro doses de liraglutide. $\mathrm{O}$ estudo, portanto, era cego para medicação ou placebo, mas não para a dose administrada. Quatrocentos e setenta e dois pacientes (84\%) completaram o estudo. Após 20 semanas, a perda de peso foi de $2,8 \mathrm{~kg}$ no grupo placebo, $4,1 \mathrm{~kg}$ no orlistate e 4,$8 ; 5,5 ; 6,3$ e 7,2 kg no grupo liraglutide, o que corresponde a uma PPSP de $4,5 \%$ no grupo que usou a maior dose de 3,0 mg. A proporção de indivíduos com mais de $5 \%$ de perda do peso inicial foi maior em quem usou liraglutide em comparação ao placebo $(61 \%$ vs. $29 \%)$. Mais indivíduos tratados com a dose de $3,0 \mathrm{mg}$ perderam mais que $5 \%$ do peso inicial do que os tratados com orlistate ( $76 \%$ vs. $44 \%)$. Houve diminuição da PA sistólica e diastólica em todos os grupos, consistente com a perda de peso. A prevalência de prédiabetes reduziu entre $84 \%$ e $96 \%$ com liraglutide 1,$8 ; 2,4$ e $3,0 \mathrm{mg}$, com uma queda na glicemia de jejum por volta de $7 \%$ a $8 \%$. A HbAlc também apresentou diminuição discreta em comparação ao placebo e orlistate, variando de $0,14 \%$ com liraglutide $1,2 \mathrm{mg}$ a $0,24 \%$ com a dose de 3,0 mg. Não houve diferença em relação aos lípides, fato que os autores atribuíram provavelmente à realização da dosagem basal somente no início do tratamento, e não na triagem três semanas antes. Considerou-se que a perda de peso conseguida nesse período inicial pode ter ocultado possíveis mudanças benéficas no perfil lipídico. Em relação à qualidade de vida, observou-se melhora nos escores de função física e de autoestima com a dose de 3,0 mg em comparação ao orlistate e placebo.

A frequência de efeitos colaterais foi discretamente maior nos grupos liraglutide 1,$8 ; 2,4$ e $3,0 \mathrm{mg}$. Os eventos mais comumente reportados foram náuseas $\mathrm{e}$ vômitos, que ocorreram sete vezes mais com as doses de 2,4 e 3,0 mg em comparação ao placebo. Na grande maioria, esses eventos eram transitórios e de leve a moderada intensidade, e sua frequência aumentava com a dose. A tendência desses efeitos era diminuir a partir da $4^{\mathrm{a}}$ semana, atingindo um platô por volta da $12^{\mathrm{a}}$ semana. A taxa de abandono global dos pacientes tomando a medicação variou de $11 \%$ a $22 \%$, sendo por volta de metade dos casos diretamente relacionados a efeitos colaterais. Oito $(2,2 \%)$ pacientes tomando liraglutide abandonaram o estudo por conta de náuseas e cinco $(1,3 \%)$ por vômitos. Alterações psiquiátricas foram ligeiramente mais frequentes nas pessoas tratadas com liraglutide $2,4 \mathrm{mg}$ e $3,0 \mathrm{mg}$ que no grupo placebo - as mais comuns sendo insônia ( 6 eventos), humor deprimido ( 3 eventos) e nervosismo ( 2 eventos). Não houve incidência maior de depressão e ansiedade no grupo tratado. A FC teve leve aumento com o uso do liraglutide (até $4 \mathrm{bpm}$ ) em comparação ao placebo e orlistate. Eventos cardiovasculares foram infrequentes e palpitações leves foram reportadas por $1 \%$ a $4 \%$ dos indivíduos recebendo a medicação. Houve um caso de fibrilação atrial em uma mulher de $5 \mathrm{l}$ anos tratada com liraglutide 3,0 mg após 140 dias, sem outros eventos graves relatados. Devido ao achado em modelos experimentais de carcinogênese aumentada de células parafoliculares de tireoide em ratos tratados com liraglutide, dosou-se a calcitonina sérica de todos os pacientes, sem nenhum efeito significativo observado. Nenhum caso de pancreatite foi descrito durante o período do estudo.

\section{Cetilistate}

O cetilistate é a segunda droga da classe dos inibidores das lipases pancreáticas e gastrointestinais (16). O orlistate é o pioneiro dessa classe, sendo liberado atualmente para tratamento a longo prazo da obesidade. $\mathrm{O}$ objetivo do uso dessas medicações é induzir um balanço energético negativo ao inibir a hidrólise dos triglicérides da dieta e, consequentemente, diminuir a absorção de monoglicérides e ácidos graxos livres. Entretanto, uma série de efeitos colaterais gastrointestinais pode limitar seu uso, como dor abdominal, fezes oleosas, incontinência fecal e flatos com descarga oleosa.

Estudos fase 2 com o cetilistate confirmaram eficácia semelhante ao orlistate. Um estudo recente de 12 semanas de duração randomizou 612 pacientes diabéticos tipo 2, IMC entre 28 e $45 \mathrm{~kg} / \mathrm{m}^{2}$, com HbAlc > 6 e $<10 \%$ para receber cetilistate $(40,80$ ou $120 \mathrm{mg}$ três vezes ao dia), orlistate $120 \mathrm{mg}$ três vezes ao dia ou placebo, com as refeições (17). Os pacientes foram estratificados de acordo com a dose de metformina ( $\leq$ ou $>1.500 \mathrm{mg} /$ dia) e eram orientados a fazer uma dieta com déficit de $500 \mathrm{kcal} /$ dia (30\% gorduras). Após 12 semanas, observou-se perda de 2,$91 ; 2,94 ; 3,88 ; 4,19$ e $3,74 \%$ do peso inicial para placebo, cetilistate $(40,80 \mathrm{e}$ $120 \mathrm{mg}$ ) e orlistate $120 \mathrm{mg}$, respectivamente (PPSP de $1,28 \%$ para cetilistate $120 \mathrm{mg}$ e de $0,83 \%$ para orlistate $120 \mathrm{mg}$ ). A perda de peso foi significativa para cetilistate 80 e $120 \mathrm{mg}$ e orlistate $120 \mathrm{mg}$, porém não para cetilistate $40 \mathrm{mg}$. Houve também redução significativa, porém discreta da HbAlc nos grupos referidos anteriormente. Não se observaram mudanças nos lípides em relação ao basal, provavelmente devido ao curto período de tratamento, assim como uso de drogas hipolipemiantes por boa parte dos pacientes. 
A maior parte dos efeitos adversos observados era de origem gastrointestinal. Nos pacientes tomando cetilistate, esses efeitos eram mais frequentes do que no placebo, porém significativamente menos do que no grupo orlistate (cerca de $30 \%$ a menos). Mais pacientes tomando orlistate abandonaram o estudo por conta de efeitos colaterais (13 pacientes orlistate $120 \mathrm{mg} v s$. 6 pacientes cetilistate $80 \mathrm{mg}$ vs. 3 pacientes cetilistate $120 \mathrm{mg}$ ), além de apresentarem maior frequência de sintomas graves. Os autores discutem que o importante em termos de tolerabilidade é a forma física da gordura no intestino e que isso pode ser modulado por diferenças estruturais entre o cetilistate e o orlistate. As diferenças entre as estruturas das duas moléculas, em termos de componentes hidrofílicos e lipofílicos, podem influenciar o modo como as moléculas interagem com as micelas de gordura no intestino. É sugerido que o orlistate, ao contrário do cetilistate, pode promover a coalescência das micelas, formando óleos e aumentando o número de efeitos adversos gastrointestinais. Ambos os grupos tiveram redução discreta dos níveis de vitamina E em relação ao placebo, sem significado clínico.

\section{TERAPIA COMBINADA}

Atualmente, não existe nenhuma medicação aprovada para o tratamento da obesidade que seja ao mesmo tempo segura e altamente efetiva (isto é, produza uma PPSP de aproximadamente $10 \%$ ou mais do peso inicial). A combinação "fen-phen" utilizada em larga escala na década de 1990 foi a que mais se aproximou desse resultado, atingindo em algumas casuísticas cerca de $10 \%$ a $15 \%$ de redução do peso inicial (4), sendo, contudo, retirada do mercado por questões de segurança. Existe uma percepção atual de muitos especialistas de que a melhor maneira de se desenvolver um tratamento seguro e eficaz para a obesidade seria por meio da combinação de duas drogas que possam controlar o apetite e promover a saciedade $(18,19)$. O peso corporal é homeostaticamente regulado para preservar o peso atual de um indivíduo. Quando o peso corporal se desvia desse nível, diversos mecanismos regulatórios são ativados para restaurar o peso aos níveis prévios. Logo, estabelecer como alvo uma determinada via molecular pode levar à perda de peso, mas respostas homeostáticas compensatórias serão ativadas, minimizando a eficácia da droga (20). Em analogia com o tratamento da HAS (por exemplo, associação de inibidor da ECA/ tiazídico) e do DM2 (por exemplo, associação de met- formina/sulfonilureia), seriam utilizadas duas substâncias com mecanismos de ação e propostas diferentes, na tentativa de maximizar o efeito desejado e, simultaneamente, diminuir a chance de efeitos colaterais (19-21). No presente momento, as combinações propostas em estágio mais avançado de desenvolvimento são: bupropiona/naltrexona, bupropiona/zonisamida, fentermina/topiramato e pramlintide/metreleptina.

\section{Bupropiona/Naltrexona}

A associação da bupropiona com a naltrexona (Contrave $^{\circledR}$ ) vem sendo estudada há alguns anos pela empresa farmacêutica Orexigen Therapeutics Inc. como potencial agente no tratamento da obesidade (22). A bupropiona é um inibidor da recaptação de dopamina e norepinefrina atualmente aprovado para tratamento de depressão e como coadjuvante da cessação do tabagismo. Seu efeito como agente redutor do peso em monoterapia já foi testado previamente, obtendo resultados modestos (PPSP de 3,7\% na dose de $400 \mathrm{mg} / \mathrm{dia}$ associada à modificação intensa de estilo de vida) (23). A naltrexona é um antagonista de receptor opioide, inicialmente aprovado como tratamento da dependência aos opiáceos e, posteriormente, da dependência ao álcool. Estudos realizados em pequeno número de pacientes com a naltrexona em monoterapia como agente antiobesidade foram frustrantes, mostrando pouca ou nenhuma redução do peso corporal (24).

A despeito de essas drogas apresentarem uma eficácia discreta, quando utilizadas isoladamente, o entendimento atual das complexas vias de regulação central e periférica do apetite (25) permitiu que se postulasse um efeito sinérgico da sua associação. $\mathrm{O}$ aumento dos níveis de dopamina e norepinefrina mediado pela bupropiona estimula a atividade neural da próopiomelanocortina (POMC). Os neurônios produtores da POMC, localizados no núcleo arqueado do hipotálamo, ao serem estimulados, levam à clivagem de dois peptídeos principais: o hormônio estimulador do $\alpha$-melanócito $(\alpha-\mathrm{MSH})$ e a $\beta$-endorfina. O aumento do $\alpha$-MSH leva à ativação do MC4R e das vias de sinalização secundárias que levam ao aumento do gasto energético e à diminuição do apetite. Em contrapartida, foi demonstrado que a $\beta$-endorfina, um opioide endógeno, é responsável por um mecanismo de autoinibição da via da POMC, resultando em um aumento da ingestão alimentar em roedores. Ao inibir os receptores opioides, a naltrexona libera os neurônios da POMC da inibição pela $\beta$-endorfina e, portanto, potencializa 
os efeitos ativadores dessa via pela bupropiona $(26,27)$. Adicionalmente, alguns estudos em ratos demonstraram que a ingestão de alimentos palatáveis (por exemplo, doces) leva a aumento dos níveis de $\beta$-endorfina no hipotálamo. Isso levou à hipótese da palatabilidade mediada pelo opioide, que postula que a liberação de opioides tem uma expressão na palatabilidade do alimento e vice-versa (24). Alguns relatos anedóticos de humanos na década de 1980 sugerem que a naltrexona, embora não exercesse efeito direto na fome, levaria a uma diminuição do sentimento prazeroso relacionado ao ato de comer, o que culminaria com a redução da ingestão alimentar (24). O efeito sinérgico dessa associação foi comprovado em estudos com ratos, em que foi demonstrada uma diminuição da ingestão de alimentos tanto em ratos magros como em ratos com obesidade induzida por dieta, em comparação à monoterapia de ambas as drogas e placebo (27).

Um estudo fase 2, duplo-cego, randomizado, de 24 semanas de duração, com 419 pacientes, comparou três doses diferentes da naltrexona de liberação imediata (IR) 16, 32 e $48 \mathrm{mg}$, em associação a bupropiona $400 \mathrm{mg}$ de liberação sustentada (SR), com placebo, bupropiona $400 \mathrm{mg}$ SR e naltrexona $48 \mathrm{mg}$ IR em monoterapia (28). Pacientes recebendo bupropiona isolada ou as três doses da combinação foram seguidos por mais 24 semanas. Em 24 semanas a perda de peso foi de $5,4 \%, 5,4 \%$ e $4,3 \%$ para a associação de bupropiona com naltrexona $16 \mathrm{mg}$ (NB16), $32 \mathrm{mg}(\mathrm{NB32})$ e 48 mg (NB48), respectivamente, contra $2,7 \%$ para a bupropiona, $1,2 \%$ para a naltrexona e $0,8 \%$ para o placebo. A menor perda de peso observada nos pacientes recebendo NB48 deveu-se à maior taxa de abandono (63\%) por efeitos colaterais nesse grupo. Após 24 semanas, não havia evidência de platô em todos os três grupos da combinação, e, na análise final de 48 semanas, a combinação NB32 atingiu maior taxa de sucesso com perda média de 6,6\% em relação ao peso inicial. Verificou-se, ainda, em outros estudos fase 2 , que a naltrexona SR resultava em menos efeitos colaterais do que a IR (27).

Portanto, os estudos fase 3 foram desenhados utilizando a naltrexona SR nas doses de 16 e $32 \mathrm{mg} /$ dia e a bupropiona SR $360 \mathrm{mg} /$ dia, em duas tomadas diárias. O COR-I randomizou 1.742 pacientes para NBl6, NB32 ou placebo, com quatro semanas de titulação da medicação e 56 semanas de duração na dose estabelecida (22). A PPSP foi de 3,7\% e 4,8\% para NBl6 e NB32, respectivamente. O COR-II testou a dose de NB32 em 1.001 pacientes, contra 495 que receberam placebo (22). Os resultados foram semelhantes aos do COR-I, com PPSP de 5,2\%. A proporção de pacientes com $\geq 5 \%$ de redução do peso inicial em relação ao placebo foi também semelhante no COR-I (48 vs. 16\%) e no COR-II (56 vs. 17\%).

As taxas de abandono foram elevadas para ambos os estudos ( $46 \%$ a $51 \%$, sem diferença em relação ao placebo), sendo cerca de metade dos casos diretamente relacionados à presença de efeitos colaterais. $\mathrm{O}$ efeito adverso mais comumente observado foi náusea, por volta de $30 \%$, em comparação a $5 \%$ a $6 \%$ no grupo placebo. A incidência acontecia principalmente nas primeiras semanas de tratamento, ainda na fase de titulação da medicação, com uma tendência de queda após a $4^{\text {a }}$ semana. Outros efeitos colaterais significativamente mais comuns do que o placebo, em ordem de frequência, foram: constipação, cefaleia, tonturas, vômitos e boca seca. Não houve incidência significativamente maior de efeitos adversos no sistema cardiovascular, nem em relação a transtornos depressivos ou ideação suicida. A PA dos pacientes usando a combinação permaneceu inalterada após 56 semanas, com uma queda discreta de $2 \mathrm{mmHg}$ no grupo placebo, assim como um aumento desprezível da FC de 1 bpm nos pacientes tratados. Foram relatados três eventos adversos considerados graves, possivelmente relacionados ao uso da droga: convulsão (um), parestesias (um) e palpitações com dispneia e ansiedade (um).

\section{Bupropiona/Zonisamida}

Embora em estágio menos avançado de desenvolvimento, a combinação de bupropiona/zonisamida também parece promissora como droga antiobesidade. A zonisamida é usada como droga antiepiléptica no Japão desde 1989, sendo liberada para esse fim nos Estados Unidos e em alguns países europeus no início dos anos 2000. Em alguns estudos de curta duração de tratamento de pacientes epilépticos com zonisamida, observou-se perda de peso como efeito colateral (29). $\mathrm{O}$ mecanismo de ação para a atividade anticonvulsivante da medicação não é totalmente esclarecido, mas acredita-se que esteja associado ao bloqueio de canais de sódio e cálcio. Evidências in vitro também demonstram que essa droga leva a aumento de atividade serotoninérgica e dopaminérgica (30). Postula-se que esse mecanismo explique, pelo menos em parte, seus efeitos como agente redutor do peso. Outra propriedade da zonisamida relativamente fraca é de inibição da atividade da anidrase carbônica. Nesse contexto, destacam-se relatos 
prévios de alteração gustativa com outros inibidores da anidrase carbônica (por exemplo, topiramato, acetazolamida), levando, portanto, a um efeito anorético.

Um estudo-piloto duplo-cego, randomizado, com 60 pacientes, mostrou após 16 semanas perda de $6,0 \%$ vs. $1,0 \%$ do peso inicial para zonisamida em monoterapia (dose habitual $400 \mathrm{mg} /$ dia) e placebo, respectivamente, em associação à dieta hipocalórica com déficit de $\mathbf{5 0 0}$ $\mathrm{kcal} /$ dia (30). Uma extensão aberta do estudo por mais 16 semanas com 37 pacientes mostrou continuação dos achados, com um resultado final de $9,4 \%$ vs. $1,8 \%$ de redução do peso inicial. A droga foi bem tolerada nesse estudo, sendo fadiga o único efeito colateral relatado com maior incidência no grupo ativo que no placebo. Conforme observado em outros estudos de pacientes epilépticos, houve aumento significativo da creatinina sérica de $0,13 \mathrm{mg} / \mathrm{dL}$ no grupo tratado contra $0,03 \mathrm{mg} /$ $\mathrm{dL}$ no grupo placebo. Em um estudo subsequente com pacientes obesos com transtorno da compulsão alimentar periódica (TCAP), a zonisamida (em doses até 600 $\mathrm{mg} /$ dia) também se mostrou eficaz tanto na redução do peso como no controle dos episódios compulsivos (31). Entretanto, colocou-se em questão a sua tolerabilidade, já que $8 / 30$ pacientes usando a droga abandonaram o estudo por efeitos adversos que incluíam queixas psicológicas (dois), alterações cognitivas (dois) e até mesmo lesão acidental com fratura óssea (dois).

O laboratório Orexigen Therapeutics Inc. resolveu também patentear a associação da zonisamida com a bupropiona $\left(\right.$ Empatic $\left.^{\circledR}\right)$. Nos estudos fase 2 realizados até agora, optou-se por testar doses mais baixas da zonisamida (120 a $360 \mathrm{mg} / \mathrm{dia}$ ) com as doses de bupropiona iguais às do Contrave ${ }^{\circledR}(360 \mathrm{mg} / \mathrm{dia}), \mathrm{em}$ duas tomadas diárias (22). Um estudo de 24 semanas de duração com 320 pacientes mostrou perda de 7,5\%; $6,1 \%$ e $1,4 \%$ do peso inicial para a associação de bupropiona com zonisamida $360 \mathrm{mg}$ (ZB360), zonisamida $120 \mathrm{mg}$ (ZB120) e placebo, respectivamente (PPSP de 6,1\% para ZB360 e 4,7\% para ZB 120) (22). Os efeitos colaterais mais comumente apresentados foram cefaleia (13\%-15\%), insônia (12\%-15\%) e náuseas (8\%-12\%). Nenhum evento adverso sério relacionado à droga ou efeito sobre a função cognitiva, depressão, ideação suicida ou ansiedade foi relatado. Atualmente, essa combinação aguarda completar os estudos de fase 3 .

\section{Fentermina/Topiramato}

A fentermina é uma substância catecolaminérgica, com propriedades de aumentar a liberação de noradrenali- na no SNC, liberada para tratamento da obesidade nos Estados Unidos desde 1959 (em doses de até $30 \mathrm{mg}$ / dia). Essa medicação também possui liberação da Anvisa (Agência Nacional de Vigilância Sanitária), porém nunca foi comercializada no Brasil (32). O topiramato é uma medicação inicialmente liberada para tratamento da epilepsia, que atualmente também é amplamente prescrita para a profilaxia da enxaqueca. Alguns estudos no início da década de 2000 comprovaram a eficácia dessa droga em reduzir o peso de pacientes obesos (em doses testadas de 64 até $384 \mathrm{mg} /$ dia) (33), fato anteriormente observado nos ensaios clínicos envolvendo pacientes epilépticos normais e obesos. A eficácia da droga aumentava muito pouco com o aumento das doses a partir de $192 \mathrm{mg} /$ dia, e com o inconveniente de aumento de efeitos adversos. Um ponto interessante observado nesses estudos é a continuação da perda de peso por até mais de um ano de tratamento, sem o platô observado geralmente por volta de seis meses com o uso das demais drogas existentes (33). O topiramato também foi testado em pacientes obesos com TCAP, com bons resultados na perda de peso e redução de escores de compulsão (34). Entretanto, apesar de mostrar-se altamente eficaz, o entusiasmo com a droga diminuiu consideravelmente devido à elevada incidência de efeitos colaterais muito pouco tolerados pelos pacientes, tais como: parestesias, alterações de memória, dificuldade de concentração e alterações do humor. Enquanto é sabido que exerce sua atividade antiepiléptica pelo bloqueio de canais de sódio e cálcio, potencialização da ação do GABA e inibição da anidrase carbônica, seu mecanismo de ação como agente redutor do peso ainda é desconhecido. Em modelos animais, o topiramato tanto reduz o apetite como interfere na eficiência da utilização de energia, ao aumentar a termogênese $\mathrm{e}$ a oxidação de gorduras (mediante o estímulo da lipoproteína lipase no tecido adiposo marrom e musculoesquelético) (33).

Ao combinar doses menores dessas medicações que agem em vias diferentes, a farmacêutica Vivus Inc. objetivava amplificar os resultados positivos e minimizar a chance de efeitos colaterais. Supostamente, o efeito estimulante leve da fentermina sobre o SNC poderia sobrepujar os efeitos negativos do topiramato sobre a memória e a cognição, por exemplo. Foram testadas três doses do Qnexa ${ }^{\circledR}$ : baixa (fentermina $3,75 \mathrm{mg} \mathrm{IR} /$ topiramato $23 \mathrm{mg} \mathrm{SR}$ ), média (fentermina 7,5 mg IR/topiramato $46 \mathrm{mg} \mathrm{SR}$ ) e alta (fentermina $15 \mathrm{mg} \mathrm{IR/topirama-}$ to $92 \mathrm{mg} \mathrm{SR}$ ). O estudo fase 2 denominado EQUATE 
avaliou 776 pacientes por um período de 28 semanas (incluindo quatro semanas de titulação da medicação), em que os pacientes foram randomizados para placebo, fentermina ou topiramato em monoterapia nas doses média e alta e Qnexa ${ }^{\circledR}$ nas doses média e alta (35). No final do estudo, os pacientes recebendo Qnexa ${ }^{\circledR}$ tanto na dose alta como na dose média perderam significativamente mais peso que a fentermina ou o topiramato dose alta em monoterapia ou placebo, comprovando, portanto, o sinergismo da associação (Qnexa alta: $-9,2 \%$; Qnexa média: $-8,5 \%$; topiramato $92 \mathrm{mg}:-6,4 \%$; fentermina $15 \mathrm{mg}:-6,1 \%$; placebo: $-1,7 \%$ ).

Recentemente, foram divulgados os resultados dos estudos fase 3 com duração de 56 semanas. O EQUIP, envolvendo 1.267 pacientes obesos com IMC $>35 \mathrm{~kg} / \mathrm{m}^{2}$, mostrou redução de $11,0 \% ; 5,1 \%$ e 1,6\% para Qnexa ${ }^{\circledR}$ dose alta, baixa e placebo, respectivamente (PPSP de 9,4\% para dose alta e 3,5\% para dose baixa) (35). O CONQUER avaliou 2.487 pacientes com IMC entre 27 e $45 \mathrm{~kg} / \mathrm{m}^{2}$ com duas ou mais comorbidades. Os resultados foram semelhantes com perda de $10,4 \% ; 8,4 \%$ e $1,8 \%$ para Qnexa ${ }^{\circledR}$ dose alta, média e placebo, respectivamente (PPSP de 8,6\% para dose alta e $6,6 \%$ para dose média) (35). Houve melhora significativa de uma série de marcadores de risco cardiovascular nos pacientes usando a medicação, incluindo: circunferência abdominal, PA sistólica e diastólica e lípides de um modo geral. Os pacientes diabéticos desse estudo tiveram redução significativa dos níveis de glicemia em jejum, HbAlc e índice HOMA em ambas as doses.

Os efeitos colaterais mais comuns, em ordem de frequência, foram: boca seca, parestesias, constipação, infecção das vias aéreas superiores, alteração do gosto e insônia. A taxa de abandono global foi de $31 \%$ a $43 \%$ para os pacientes tomando Qnexa ${ }^{\circledR}$ e de $47 \%$ para os pacientes do grupo placebo. Dezoito por cento dos pacientes tomando a dose alta de Qnexa ${ }^{\circledR}$ abandonaram o estudo por efeitos colaterais contra $9 \%$ do grupo placebo. Não foi descrita alteração clinicamente significativa na função cognitiva, escalas de depressão e ansiedade, ou efeitos em habilidades psicomotoras nos pacientes tomando a medicação. Não está bem esclarecido se a menor incidência de efeitos adversos com o Qnexa ${ }^{\circledR}$ está relacionada ao uso de uma menor dose do topiramato do que em estudos prévios ou ao fato de tratar-se de uma formulação SR.

\section{Pramlintide/Metreleptina}

O controle da homeostase energética e do peso corporal envolve complexas interações entre o SNC e sinais neuro-hormonais periféricos do tecido adiposo, pâncreas e TGI (25). Essas interações incluem a integração de sinais de adiposidade de longo prazo, tais como insulina e leptina, e sinais de saciedade de curto prazo, tais como amilina, peptídeo YY, incretinas e colecistoquinina. Os primeiros possuem secreção tônica pelo pâncreas e tecido adiposo, respectivamente, enquanto os segundos possuem secreção episódica em resposta à presença de alimentos no TGI.

A amilina é um hormônio peptídico de 37 aminoácidos cossecretado com a insulina pelas células $\beta$-pancreáticas, que se liga a receptores no rombencéfalo (cérebro posterior, estrutura que compreende o bulbo raquidiano, ponte e cerebelo), levando a aumento da saciedade e diminuição da ingestão alimentar (36). Em estudos prévios em pacientes obesos em monoterapia, esse hormônio mostrou perda de peso mantida $\mathrm{e}$ prolongada (37).

A leptina é um neuro-hormônio secretado predominantemente pelos adipócitos, que se liga a receptores no hipotálamo, apresentando papel-chave na regulação da homeostase energética a longo prazo (36). Sabe-se que humanos com deficiência desse hormônio apresentam hiperfagia severa e obesidade grave, e que a reposição de metil-leptina humana recombinante (metreleptina) nesses pacientes leva a uma reversão quase que completa desse fenótipo. Entretanto, em pacientes obesos sem deficiência de leptina, a administração dessa substância em monoterapia, mesmo em doses farmacológicas elevadas, falhou em produzir perda de peso substancial (38).

É importante o entendimento de como essas substâncias interagem umas com as outras, tanto na fase dinâmica de perda de peso como na fase de peso reduzido já estabelecida. Os níveis circulantes de leptina caem rapidamente após a perda de peso induzida por dieta, suscitando uma série de respostas contrarregulatórias hormonais, metabólicas e autonômicas responsáveis em manter o peso inicial (39). Este é um dos mecanismos compensatórios que dificultam a progressão ou mesmo a manutenção de uma determinada redução do peso corporal. Interessantemente, demonstrou-se previamente que a restauração dos níveis basais de leptina, por meio da reposição de metreleptina em humanos submetidos à perda de peso induzida por dieta, contribui para atenuar essas respostas contrarregulatórias da perda de peso (39). Nesse estudo, Rosenbaum e cols. (39) demonstraram elegantemente que, após a administração de metreleptina, o gasto energético, a eficiên- 
cia de trabalho do músculo esquelético, o tônus do sistema nervoso simpático e os níveis circulantes de T3 e T4 retornavam aos níveis basais pré-perda de peso (39).

A queda da leptina induzida por dieta também contribui para diminuir o efeito anorexigênico dos sinais de saciedade no rombencéfalo. Por outro lado, é crescente o reconhecimento de que os sinais do rombencéfalo podem exercer efeitos importantes na sinalização da leptina no hipotálamo (36).

Estudos pré-clínicos em ratos com obesidade induzida por dieta mostraram que o tratamento combinado com amilina e leptina levou a uma resposta pronunciada e sinérgica na redução da ingestão alimentar (até $45 \%$ ) e do peso corporal (até 15\%) (40). Comprovou-se que a perda de peso era gordura-específica e não era acompanhada das reduções do gasto energético e da oxidação de gorduras habitualmente observadas com a restrição calórica. Esses dados corroboravam, portanto, a hipótese de que a associação do pramlintide (análogo da amilina) com a metreleptina teria um potencial papel no tratamento de humanos obesos.

O primeiro ensaio clínico com a associação envolveu 177 pacientes obesos com IMC entre 30 e $35 \mathrm{~kg} / \mathrm{m}^{2}$ (81\%), ou pacientes com sobrepeso com IMC entre 27 e $30 \mathrm{~kg} / \mathrm{m}^{2}$ com aumento de circunferência abdominal (homens $>102 \mathrm{~cm}$, mulheres $>88 \mathrm{~cm}$ ) $(36)$. O estudo teve duração total de 24 semanas, sendo as quatro semanas iniciais de titulação da dose do pramlintide (180 $\operatorname{mcg} 2 \mathrm{x} /$ dia nas primeiras duas semanas e $360 \mathrm{mcg} 2 \mathrm{x} /$ dia nas próximas duas, via subcutânea), em associação a uma dieta com déficit calórico de $40 \%$. Após esse período, os pacientes que haviam perdido de $2 \%$ a $8 \%$ do peso inicial eram randomizados numa proporção de l:2:2 para receber metreleptina $5 \mathrm{mg} 2 \mathrm{x} /$ dia / placebo, pramlintide $360 \mathrm{mcg} 2 \mathrm{x} /$ dia / placebo ou pramlintide $360 \mathrm{mcg} 2 \mathrm{x} /$ dia / metreleptina $5 \mathrm{mg} \mathrm{2x} /$ dia, respectivamente. Segundo os autores, no momento do estudo não havia ampolas de placebo suficientes, o que justificou a não inclusão de um braço com esse grupo. Centro e trinta e nove pacientes preenchiam os critérios de inclusão após as quatro semanas iniciais. Ao final das 24 semanas, a perda de peso foi significativamente maior no grupo recebendo a terapia combinada de pramlintide/metreleptina $(-12,7 \%)$ do que pramlintide $(-8,4 \%)$ ou metreleptina $(-8,2 \%)$ isoladamente. Tais achados foram divulgados em relação à população que completou o estudo, e os autores não divulgaram numericamente os dados em relação à análise de intenção de tratar, embora a diferença também tenha sido significativa. Ape- sar de dentro da faixa da normalidade no rastreamento, houve tendência de melhora dos níveis de triglicérides, colesterol total, LDL-colesterol, glicemia, insulinemia e resistência insulínica aferida pelo HOMA.

A maioria dos efeitos colaterais resumia-se a reações adversas no local da injeção (dor, eritema; $58,9 \%$ ) e náuseas $(12,5 \%)$. Outros efeitos colaterais foram muito pouco frequentes, ocorrendo em até $5 \%$ dos casos, e incluíam nasofaringite, cefaleia, constipação, diarreia etc. A taxa de abandono global foi indiferente entre os grupos, variando de $30 \%$ a $34 \%$. Um paciente em cada grupo abandonou por reações adversas no local da injeção e um paciente no grupo da terapia combinada abandonou por náuseas, sendo que quatro pacientes já haviam abandonado também por náuseas, nas semanas iniciais de titulação do pramlintide.

\section{CONSIDERAÇÕES FINAIS}

O crescimento da obesidade nas últimas décadas no Brasil e no mundo é alarmante. É visível também o aumento exponencial dos casos de pacientes submetidos à cirurgia bariátrica, refletindo um esforço dos médicos em tentar reverter potenciais complicações associadas à doença e ao mesmo tempo expondo a pequena gama de opções farmacológicas disponíveis para o tratamento clínico.

Atualmente, no Brasil, existem cinco opções de drogas disponíveis para tratamento da obesidade. São elas: dietilpropiona, mazindol, femproporex, sibutramina e orlistate (32), sendo as duas últimas liberadas para tratamento a longo prazo. O orlistate é uma droga com eficácia pequena na redução de peso, mas tem a seu favor o fato de ser isento de efeitos adversos no sistema cardiovascular, podendo ser usado com segurança nessa população. A sibutramina é a droga com mais estudos realizados até hoje e também uma das mais prescritas, com bons resultados e um perfil favorável de efeitos colaterais. Entretanto, recentemente foram reportados dados preliminares do estudo SCOUT (Sibutramine Cardiovascular OUTcomes Trial), que objetivava avaliar se a medicação era capaz de reduzir eventos cardiovasculares (incluindo IAM, AVC, parada cardiorrespiratória revertida ou morte) em uma população obesa de alto risco (pacientes com DM2 e outro fator de risco, pacientes com histórico de evento cardiovascular prévio, pacientes com DM2 e outro fator de risco e histórico de evento cardiovascular prévio). Houve um aumento discreto, porém significativo, desses desfechos 
no grupo de pacientes recebendo a sibutramina (11,4\% vs. 10\%) (41), o que motivou a EMEA (European Medicines Agency) a suspender a comercialização da droga na Europa (42).

O FDA (Food and Drug Administration) e a Anvisa optaram por não suspender a droga, emitindo um parecer reforçando contra o uso da medicação em pacientes com essas características, o que já era previsto anteriormente em bula $(41,43)$. Resta ainda a análise completa dos dados do estudo para avaliar eventuais diferenças entre os subgrupos de pacientes. Portanto, no presente momento, permanece a máxima de que é fundamental a avaliação criteriosa de médicos especialistas, pesando os riscos e os benefícios do uso dessa medicação e levando em consideração a característica de cada paciente.

Tendo em vista esse acontecimento, assim como a recente retirada do rimonabanto do mercado por efeitos negativos neuropsiquiátricos, a tendência das agências regulatórias é aumentar cada vez mais o nível de exigência para a aprovação de novas medicações.

Nesta revisão, foram descritas oito novas drogas antiobesidade com potencial de serem aprovadas para uso em curto e a médio prazo. A tabela 1 resume os mecanismos de ação dessas medicações e a tabela 2 resume os principais resultados dos ensaios clínicos. A figura 1 ilustra a PPSP observada nos principais ensaios clínicos realizados com essas drogas até o presente momento, embora obviamente haja uma grande heterogeneidade em relação ao número de pacientes e à duração do seguimento. Para fins de comparação, foram acrescentados dados da sibutramina e orlistate de uma metanálise de 2007. Dados do cetilistate foram ocultados por tratar-se de curta duração e da combinação pramlinti$\mathrm{de} /$ metreleptina por não apresentarem grupo placebo, não permitindo, portanto, comparação com as demais drogas.

A lorcaserina e as combinações de bupropiona/naltrexona $\left(\right.$ Contrave $\left.^{\circledR}\right)$ e fentermina/topiramato (Qne$\left.\mathrm{xa}^{\circledR}\right)$ estão em estágio mais avançado de desenvolvimento, e tanto a lorcaserina como o Qnexa ${ }^{\circledR}$ já submeteram pedido de aprovação ao FDA (new drug application) no final de 2009. A expectativa é, portanto, que caso o FDA não faça mais exigências em relação ao perfil de segurança e tolerabilidade, essas medicações estejam disponíveis no mercado americano a partir do final de 2010 ou início de 2011 . O Contrave ${ }^{\circledR}$ deve solicitar pedido de aprovação em breve e as demais medicações ainda precisam passar pelos estudos de fase 3 antes de chegar nesse estágio. É importante frisar que as infor-
Tabela 1. Drogas propostas e mecanismos de ação

\begin{tabular}{ll}
\hline Droga(s) & \multicolumn{1}{c}{ Mecanismo de ação } \\
\hline Lorcaserina & Agonista serotoninérgico seletivo receptor \\
& 5-HT2c (estimulante da POMC) \\
Tesofensina & Inibidor da recaptação de noradrenalina, \\
& dopamina e serotonina \\
Liraglutide & Análogo do GLP-1 $\downarrow$ esvaziamento gástrico \\
& $\uparrow$ saciedade $\downarrow$ apetite \\
Cetilistate & Inibidor das lipases pancreática e \\
& gastrointestinal \\
Bupropiona + Naltrexona & Bupropiona: inibição da recaptação de \\
& noradrenalina e dopamina (estimulante da \\
& POMC) \\
& $\begin{array}{l}\text { Naltrexona: antagonista do receptor opioide } \\
\text { (impede a autoinibição da } \beta \text {-endorfina sobre a } \\
\text { via POMC) }\end{array}$ \\
& Bupropiona: inibição da recaptação de \\
noradrenalina e dopamina (estimulante da \\
POMC) \\
Zonisamida: aumento dos níveis de serotonina \\
e dopamina (estimulante da POMC e inibidor \\
do AgRP) \\
Fentermina: aumento da liberação de \\
noradrenalina \\
Topiramato: mecanismo desconhecido. Em \\
modelos animais $\downarrow$ apetite $\uparrow$ termogênese e \\
oxidaçãa de gorduras \\
Pramlintide: análogo da amilina $\uparrow$ saciedade \\
$\downarrow$ ingestão alimentar \\
Metreleptina: reverte os efeitos da perda de \\
peso na redução do gasto energético; possui \\
ação sinérgica com o pramlintide na \\
sinalização anorexigênica no SNC
\end{tabular}

POMC: pró-opiomelanocortina; GLP-1: glucagon-like peptide 1 (peptídeo semelhante ao glucagon 1); AgRP: Agouti-related peptide (peptídeo relacionado ao Agouti); SNC: sistema nervoso central.

Tabela 2. Resumo dos resultados dos principais ensaios clínicos

\begin{tabular}{lcccc}
\hline Droga(s) & Estudos & $\begin{array}{c}\mathbf{N}^{\mathbf{0}} \\
\text { pacientes }\end{array}$ & $\begin{array}{c}\text { Duração } \\
\text { (semanas) }\end{array}$ & $\begin{array}{c}\text { PPSP } \\
\text { (\%) }\end{array}$ \\
\hline Lorcaserina & BLOOM (Fase 3) & 3.182 & 52 & 3,6 \\
& BLOSSOM (Fase 3) & 4.008 & 52 & 3,1 \\
Tesofensina & TIPO-1 (Fase 2) & 203 & 24 & 9,2 \\
Liraglutide & Fase 2 & 564 & 20 & 4,5 \\
Cetilistate & Fase 2 & 612 & 12 & 1,3 \\
Bupropiona + & COR-I (Fase 3) & 1.742 & 60 & 4,8 \\
Naltrexona & COR-II (Fase 3) & 1.496 & 60 & 5,2 \\
Bupropiona + & Fase 2 & 320 & 24 & 6,1 \\
Zonisamida & & & & \\
Fentermina + & EQUIP (Fase 3) & 1.267 & 56 & 9,4 \\
Topiramato & CONQUER (Fase 3) & 2.487 & 56 & 8,6 \\
Pramlintide + & Fase 2 & 139 & 24 & - \\
Metreleptina & & & & \\
\hline
\end{tabular}

PPSP: perda de peso subtraída do placebo; lorcaserina $20 \mathrm{mg} /$ dia; tesofensina $0,5 \mathrm{mg} / \mathrm{dia}$; liraglutide $3,0 \mathrm{mg} / \mathrm{dia}$; cetilistate $360 \mathrm{mg} / \mathrm{dia}$; (bupropiona $360 \mathrm{mg} / \mathrm{naltrexona} 32 \mathrm{mg}$ )/dia; (bupropiona $360 \mathrm{mg} / 20 n i s a m i d a 360 \mathrm{mg} /$ /dia; (fentermina $15 \mathrm{mg} /$ topiramato $92 \mathrm{mg}$ )/dia; (pramlintide $720 \mathrm{mcg} / \mathrm{metreleptina} 10 \mathrm{mg}$ )/dia. 


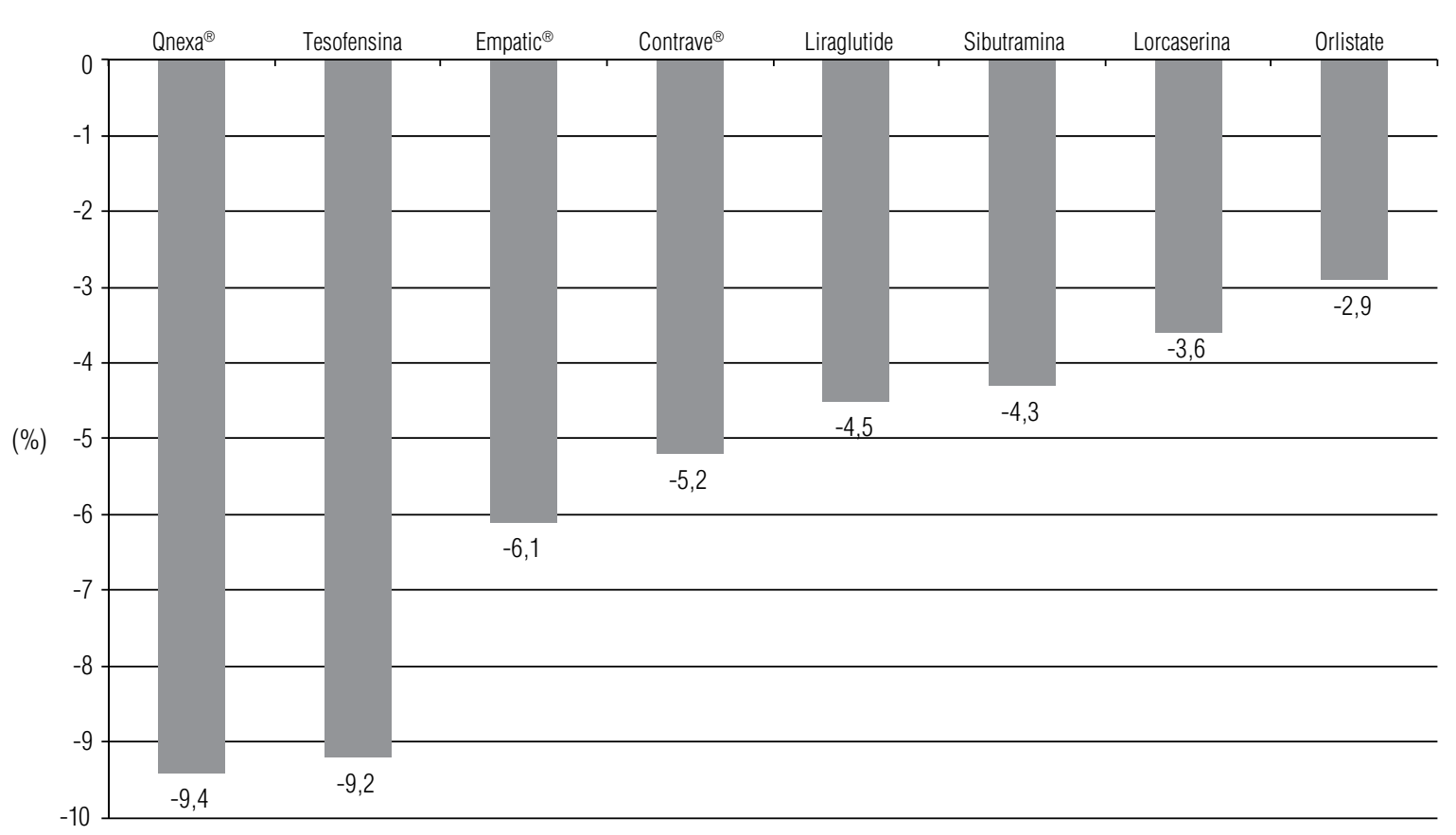

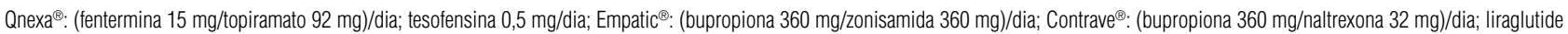
$3,0 \mathrm{mg} / \mathrm{dia} ;$ sibutramina $15 \mathrm{mg} / \mathrm{dia}$; lorcaserina $20 \mathrm{mg} / \mathrm{dia}$; orlistate $360 \mathrm{mg} / \mathrm{dia}$.

Figura 1. Análise comparativa - perda de peso subtraída do placebo.

mações apresentadas dos estudos fase 3 da lorcaserina, Qnexa ${ }^{\circledR}$ e Contrave ${ }^{\circledR}$ e fase 2 do Empatic $^{\circledR}$ foram obtidas diretamente de páginas da Internet das indústrias farmacêuticas $(8,22,35)$, não tendo passado até o momento, portanto, pela avaliação criteriosa de revisores de revistas científicas.

A lorcaserina é uma droga que não acrescenta muito em termos de potência em relação às atualmente existentes, mas pelos resultados apresentados parece apresentar ótima tolerabilidade, sem o inconveniente de desenvolvimento de valvulopatia e hipertensão pulmonar visto com as extintas fenfluramina e a dexfenfluramina. Supostamente, portanto, existe uma possibilidade de associação com a fentermina com o objetivo de maximização de resultados, em analogia à combinação "fen-phen".

A tesofensina exibiu, no estudo inicial fase 2, resultados animadores. Excluindo a dose de $1,0 \mathrm{mg}$, as demais doses estudadas $(0,25$ e $0,5 \mathrm{mg})$ apresentaram boa tolerabilidade e resultados excelentes, tendo a dose de 0,5 mg alcançado cerca do dobro da PPSP obtida com a sibutramina, por exemplo. Com as doses menores de 0,25 e $0,5 \mathrm{mg}$ testadas no estudo de fase 2 , houve aumento dose-dependente da FC e manutenção dos níveis de PA em relação ao basal. Levando-se em consideração que a perda de peso por si só é suficiente para levar a melhoras expressivas dos níveis de PA, o fato de esses níveis permanecerem inalterados sinaliza para um potencial hipertensor da medicação. Em função da similaridade química entre a tesofensina e a sibutramina, existem especulações de que a droga possa apresentar riscos cardiovasculares inesperados relacionados a ela. Entretanto, isso é puramente especulativo e deverá ser abordado de maneira meticulosa nos estudos fase 3 de grande escala a serem realizados.

O liraglutide já se encontra aprovado para o tratamento de diabéticos tipo 2, em doses de até $1,8 \mathrm{mg} /$ dia, tanto na Europa como nos Estados Unidos. O estudo-piloto realizado com essa medicação em pacientes obesos não diabéticos mostra perda de peso razoável, com doses mais altas de até $3,0 \mathrm{mg}$, porém com uma elevada incidência de náuseas no grupo tratado. Embora essa incidência tenda a diminuir com o passar do tempo, esse efeito colateral inconveniente associado ao fato de tratar-se de uma medicação injetável pode limitar o seu uso. Permanece, todavia, como uma opção excelente no manejo de obesos diabéticos e fica também como alternativa nos obesos não diabéticos, principalmente aqueles com contraindicação ou intolerância a outras medicações.

O cetilistate apresenta eficácia discreta e pouco acrescenta ao arsenal terapêutico já disponível, mas fica também como alternativa em pacientes com contraindi- 
cação a outras medicações, notadamente em pacientes metabólicos de alto risco cardiovascular, com a vantagem de apresentar menos efeitos adversos gastrointestinais em relação ao orlistate - dado que precisa ser confirmado em estudos de maior escala.

A terapia combinada aparece como promessa de tratamento antiobesidade ao agir em vias diferentes de regulação do apetite e gasto energético. O objetivo final é maximizar resultados, minimizar efeitos adversos e romper o platô precoce de perda de peso por volta de seis meses visto com as medicações atualmente disponíveis.

A combinação de bupropiona/naltrexona apresenta resultados discretamente superiores aos da sibutramina. Essa associação traz como vantagem pouca interação com o sistema cardiovascular e como desvantagem uma taxa razoável de efeitos colaterais, principalmente náuseas, que tendem a melhorar com o passar do tempo. Tratase, talvez, de medicação de escolha em casos de obesos tabagistas ou com problemas relacionados ao alcoolismo.

A combinação de bupropiona/zonisamida apresentou também, no estudo inicial de fase 2 , bons resultados e boa tolerabilidade. Entretanto, mais dados são necessários para confirmar a real eficácia e segurança dessa associação.

A combinação de fentermina/topiramato mostrou resultados excelentes em grande número de pacientes testados e, aparentemente, apresentou melhor tolerabilidade do que o topiramato em monoterapia. É incerto se isso se deveu ao uso da formulação SR do topiramato ou a menores doses utilizadas, mas as experiências prévias negativas do topiramato em monoterapia, com alta incidência de efeitos adversos, incluindo risco aumentado de suicídio e alterações cognitivas e de memória, trazem certa preocupação.

A combinação de pramlintide/metreleptina aparece como promessa de farmacoterapia neuro-hormonal contra a obesidade. É a primeira vez que se aplica na prática, com fins terapêuticos, o vasto conhecimento que se adquiriu nas últimas décadas sobre as complexas vias de regulação centrais e periféricas da homeostase energética. Embora tenha apresentado resultados positivos, comprovando o sinergismo da associação, a ausência do grupo placebo no estudo inicial não permite estimar a sua real eficácia e potência. Tal dado, assim como a aderência ao esquema de administração injetável, será avaliado nos grandes ensaios clínicos a serem desenvolvidos.

Por fim, deve-se ter em mente que, apesar de os dados apresentados trazerem grande esperança aos médicos que lidam no dia a dia com esse enorme problema, sempre pode haver divulgação de informações tendenciosas. Esses ensaios clínicos passam por rigorosas avaliações dos órgãos regulatórios, contudo, somente a prática clínica e anos de experiência com uso das medicações que vierem a ser aprovadas trarão à tona os verdadeiros benefícios e as eventuais mazelas a elas relacionadas.

Declaração: os autores declaram não haver conflitos de interesse científico neste estudo.

\section{REFERÊNCIAS}

1. Rucker D, Padwal R, Li SK, Curioni C, Lau DC. Long term pharmacotherapy for obesity and overweight: updated meta-analysis. BMJ. 2007;335(7631):1194-9.

2. Coutinho W. The first decade of sibutramine and orlistat: a reappraisal of their expanding roles in the treatment of obesity and associated conditions. Arq Bras Endocrinol Metabol. 2009;53(2):262-70.

3. Sjöström L, Narbro K, Sjöström CD, Karason K, Larsson B, Wedel $\mathrm{H}$, et al.; Swedish Obese Subjects Study. Effects of bariatric surgery on mortality in Swedish obese subjects. N Engl J Med. 2007;357(8):741-52.

4. Weintraub M, Sundaresan PR, Madan M, Schuster B, Balder A, Lasagna $L$, et al. Long-term weight control study. I (weeks 0 to 34). The enhancement of behavior modification, caloric restriction, and exercise by fenfluramine plus phentermine versus placebo. Clin PharmacolTher. 1992;51(5):586-94.

5. Connolly HM, Crary JL, McGoon MD, Hensrud DD, Edwards BS, Edwards WD, et al. Valvular heart disease associated with fenfluramine-phentermine. N Engl J Med. 1997;337(9):581-8.

6. Smith SR, Prosser WA, Donahue DJ, Morgan ME, Anderson CM, Shanahan WR; APD356-004 Study Group. Lorcaserin (APD356), a selective $5-\mathrm{HT}(2 \mathrm{C})$ agonist, reduces body weight in obese men and women. Obesity (Silver Spring). 2009;17(3):494-503.

7. Bays HE. Lorcaserin and adiposopathy: $5-\mathrm{HT} 2 \mathrm{c}$ agonism as a treatment for 'sick fat' and metabolic disease. Expert Rev Cardiovasc Ther. 2009;7(11):1429-45.

8. Arena Pharmaceuticals, Inc. [homepage na Internet]. Lorcaserin for weight management [atualizada em 2010 Jan 5; acesso em 2010 Fev 5]. Disponível em: http://www.arenapharm.com/wt/page//ho.html

9. Astrup A, Meier DH, Mikkelsen BO, Villumsen JS, Larsen TM. Weight loss produced by tesofensine in patients with Parkinson's or Alzheimer's disease. Obesity (Silver Spring). 2008;16(6):1363-9.

10. Astrup A, Madsbad S, Breum L, Jensen TJ, Kroustrup JP, Larsen TM. Effect of tesofensine on bodyweight loss, body composition, and quality of life in obese patients: a randomised, double-blind, placebo-controlled trial. Lancet. 2008;372(9653):1906-13.

11. NeuroSearch A/S [homepage na Internet]. Tesofensine [atualizado em 2010 Fev 5; citado em 2010 Mar 16]. Disponível em: http:// www.neurosearch.dk/Default.aspx?ID=118

12. Degn KB, Juhl CB, Sturis J, Jakobsen G, Brock B, Chandramouli V, et al. One week's treatment with the long-acting glucagon-like peptide 1 derivative liraglutide (NN2211) markedly improves 24-h glycemia and alpha- and beta-cell function and reduces endogenous glucose release in patients with type 2 diabetes. Diabetes. 2004;53(5):1187-94.

13. Vilsbøll T, Zdravkovic M, Le-Thi T, Krarup T, Schmitz O, Courrèges $\mathrm{JP}$, et al. Liraglutide, a long-acting human glucagon-like peptide-1 analog, given as monotherapy significantly improves glycemic control and lowers body weight without risk of hypoglycemia in patients with type 2 diabetes. Diabetes Care. 2007;30(6):1608-10. 
14. Flint A, Raben A, Astrup A, Holst JJ. Glucagon-like peptide 1 promotes satiety and suppresses energy intake in humans. J Clin Invest. 1998;101(3):515-20.

15. Astrup A, Rössner S, Van Gaal L, Rissanen A, Niskanen L, Al Hakim M, et al.; NN8022-1807 Study Group. Effects of liraglutide in the treatment of obesity: a randomised, double-blind, placebocontrolled study. Lancet. 2009;374(9701):1606-16.

16. Padwal R. Cetilistat, a new lipase inhibitor for the treatment of obesity. Curr Opin Investig Drugs. 2008;9(4):414-21.

17. Kopelman P, Groot Gde H, Rissanen A, Rossner S, Toubro S, Palmer R, et al. Weight loss, HbA1c reduction, and tolerability of cetilistat in a randomized, placebo-controlled phase 2 trial in obese diabetics: comparison with orlistat (Xenical). Obesity (Silver Spring). 2010;18(1):108-15.

18. Klonoff DC, Greenway F. Drugs in the pipeline for the obesity market. J Diabetes SciTechnol. 2008;2(5):913-8.

19. Mancini MC, Halpern A. Investigational therapies in the treatment of obesity. Expert Opin Investig Drugs. 2006;15(8):897-915.

20. Jones D. Novel pharmacotherapies for obesity poised to enter market. Nat Rev Drug Discov. 2009;8(11):833-4.

21. Zanella MT, Ribeiro Filho FF. Emerging drugs for obesity therapy. Arq Bras Endocrinol Metabol. 2009;53(2):271-80.

22. OrexigenTherapeutics, Inc [homepage na Internet]. Contrave and Empatic [atualizado em 2010 Fev 5; citado em 2010 Mar 16]. Disponível em: http://www.orexigen.com/

23. Anderson JW, Greenway FL, Fujioka K, Gadde KM, McKenney J, O'Neil PM. Bupropion SR enhances weight loss: a 48-week double-blind, placebo-controlled trial. Obes Res. 2002;10(7):633-41.

24. Lee MW, Fujioka K. Naltrexone for the treatment of obesity: review and update. Expert Opin Pharmacother. 2009;10(11):1841-5.

25. Simpson KA, Martin NM, Bloom SR. Hypothalamic regulation of food intake and clinical therapeutic applications. Arq Bras Endocrinol Metabol. 2009;53(2):120-8.

26. Greenway FL, Whitehouse MJ, Guttadauria M, Anderson JW, Atkinson RL, Fujioka K, et al. Rational design of a combination medication for the treatment of obesity. Obesity (Silver Spring). 2009;17(1):30-9.

27. Padwal R. Contrave, a bupropion and naltrexone combination therapy for the potential treatment of obesity. Curr Opin Investig Drugs. 2009;10(10):1117-25.

28. Greenway FL, Dunayevich E, Tollefson G, Erickson J, Guttadauria M, Fujioka K, et al.; NB-201 Study Group. Comparison of combined bupropion and naltrexone therapy for obesity with monotherapy and placebo. J Clin Endocrinol Metab. 2009;94(12):4898-906.

29. Oommen KJ, Mathews S. Zonisamide: a new antiepileptic drug. Clin Neuropharmacol. 1999;22(4):192-200.

30. Gadde KM, Franciscy DM, Wagner HR 2nd, Krishnan KR. Zonisamide for weight loss in obese adults: a randomized controlled trial. JAMA. 2003;289(14):1820-5.
31. McElroy SL, Kotwal R, Guerdjikova Al, Welge JA, Nelson EB, Lake $\mathrm{KA}$, et al. Zonisamide in the treatment of binge eating disorder with obesity: a randomized controlled trial. J Clin Psychiatry. 2006;67(12):1897-906.

32. Mancini MC, Halpern A. Pharmacological treatment of obesity. Arq Bras Endocrinol Metabol. 2006;50(2):377-89.

33. Astrup A, Toubro S. Topiramate: a new potential pharmacological treatment for obesity. Obes Res. 2004;12 Suppl:167S-73S.

34. Leombruni P, Lavagnino L, Fassino S. Treatment of obese patients with binge eating disorder using topiramate: a review. Neuropsychiatr Dis Treat. 2009;5:385-92.

35. Vivus, Inc. [homepage na Internet]. Qnexa obesity [atualizado em 2010 Fev 5; citado em 2010 Mar 16]. Disponível em: http://www. vivus.com/pipeline/qnexa-obesity

36. Ravussin E, Smith SR, Mitchell JA, Shringarpure R, Shan K, Maier H, et al. Enhanced weight loss with pramlintide/metreleptin: an integrated neurohormonal approach to obesity pharmacotherapy. Obesity (Silver Spring). 2009;17(9):1736-43.

37. Smith SR, Aronne LJ, Burns CM, Kesty NC, Halseth AE, Weyer C. Sustained weight loss following 12-month pramlintide treatment as an adjunct to lifestyle intervention in obesity. Diabetes Care. 2008;31(9):1816-23.

38. Heymsfield SB, Greenberg AS, Fujioka K, Dixon RM, Kushner R, Hunt T, et al. Recombinant leptin for weight loss in obese and lean adults: a randomized, controlled, dose-escalation trial. JAMA. 1999;282(16):1568-75.

39. Rosenbaum M, Goldsmith R, Bloomfield D, Magnano A, Weimer L, Heymsfield S, et al. Low-dose leptin reverses skeletal muscle, autonomic, and neuroendocrine adaptations to maintenance of reduced weight. J Clin Invest. 2005;115(12):3579-86.

40. Trevaskis JL, Coffey $\mathrm{T}$, Cole R, Lei C, Wittmer C, Walsh B, et al. Amylin-mediated restoration of leptin responsiveness in dietinduced obesity: magnitude and mechanisms. Endocrinology. 2008;149(11):5679-87.

41. Early Communication about an Ongoing Safety Review of Meridia (sibutramine hydrochloride), U.S. Food and Drug Administration [homepage na Internet]. [atualizado em 2009 Nov 20; citado em 2010 Mar 16]. Disponível em: http://www.fda.gov/Drugs/DrugSafety/PostmarketDrugSafetyInformationforPatientsandProviders/DrugSafetyInformationforHeathcareProfessionals/ ucm 191650.htm

42. Press Release, European Medicines Agency [homepage na Internet]. [atualizado em 2010 Jan 21; citado em 2010 Mar 16]. Disponivel em: http://www.ema.europa.eu/pdfs/human/referral/ sibutramine/3940810en.pdf

43. Novas contra-indicações de uso da sibutramina, ALERTA SNVS/ Anvisa/Nuvig/Gfarm $n^{\circ} 01$ [homepage na Internet]. [atualizado em 2010 Jan 28; citado em 2010 Mar 16]. Disponível em: http:// portal.anvisa.gov.br/wps/wcm/connect/5ed68b004131ef458f09df b3f1e98cad/Alerta_n1sibutramina.pdf?MOD=AJPERES 